\title{
The General Practice Airways Group (GPIAG) and the Primary Care Respiratory Journal
}

\begin{abstract}
$\mathrm{A}$ $t$ the 13th Annual General Meeting we decided to change the name of our group to the General Practice Airways Group (GPIAG) and that of our journal to the Primary Care Respiratory Journal. Although asthma is still the commonest childhood medical condition managed in primary care, we have changed our name to acknowledge our increased role in managing other respiratory conditions, such as rhinitis, COPD (chronic obstructive pulmonary disease), smoking cessation, respiratory infections and allergies. This change has coincided with our extremely successful International Primary Care Respiratory Conference where over 90 papers on all aspects of respiratory diseases were presented. Details of this conference are being summarised in the form of a supplement, which will be published in the next few months.
\end{abstract}

This issue of our journal has four original papers. The review by Mike Thomas (Prim. Care Respir. J. 2000; 9(1): 4-7) provides academic background and practical information on lower respiratory tract infections and illness in primary care. The literature review raises important questions related to the management of patients presenting to their general practitioner with acute lower respiratory tract illness. Thomas highlights the fact that treatment is often empirical and commenced without investigations. He emphasises the need for careful clinical examination to diagnose, and therefore treat, community-acquired pneumonia in primary care. He also provides practical advice on the choice of treatments and guidance on referral to colleagues in secondary care.

The paper by Jennifer Cropper et al. (Prim. Care Respir. J. 2000; 9(1): 8-11) is part of a long-term prospective study of asthma. They present a method for calculating the cost of respiratory illness and healthcare utilisation in primary care. Data from records of 713 children (mean age 7.5 years) in two general practice populations in south Manchester were compared with responses to a postal respiratory questionnaire aimed at predicting likelihood of asthma. The data suggest strongly that the questionnaire may be used to predict the cost and need for primary healthcare provision, however this will need to be repeated in order to determine its suitability for application to other areas. According to the authors, more data are forthcoming with regard to healthcare utilisation and costs in secondary care, for this population.

The second research paper in this issue by Christopher Hand et al. (Prim. Care Respir. J. 2000; 9(1): 12-15) is a fine example of the type of careful research work emanating from primary care. This group has developed a research questionnaire, which seems able to determine asthma patients' beliefs about their inhaler treatments. Clearly a major step towards improving patients' understanding and adherence to medication.

Finally, the third paper in our series on understanding statistics by Sheikh and Cook, helps clarify the mysteries of hypothesis testing in research. They discuss significance tests, the type of tests to be used according to the nature of the data and the sort of errors in interpreting significance tests that may occur.

\author{
Mark L Levy \\ Editor \\ marklevy@gpiag-asthma.org
}

\author{
Editor: Dr Mark Levy \\ Editorial Board: \\ Dr Chris Griffiths \\ Dr John Haughney \\ Dr Robert McKinley \\ Dr Paul Stephenson \\ International Editorial \\ Advisers: \\ Dr Alan Kaplan (Canada) \\ Professor James Reid \\ (New Zealand) \\ Dr Ron Tomlins (Australia) \\ Professor Onno van Schayck \\ (The Netherlands)
}

Primary Care Respiratory Journal is published on behalf of the General Practice Airways Group (GPIAG) by: Strategic Medical Publishing Action International House

Crabtree Office Village

Eversley Way, Egham

Surrey TW20 8RY

The GPIAG operates independently of any commercial company. However, it does generate money from pharmaceutical companies to finance the Group's Secretariat, Annual Scientific Meeting, the Research Unit and this journal.

ISSN 1471-4418

Journals Manager:

Jane Mortlock

Commissioning Editor:

Fiona McGuinness

The views expressed in this journal are not necessarily those of the General Practice Airways Group or the publisher.

Editorial decisions are independent of commercial restraints.

() GPIAG Committee. All rights reserved. No part of this publication may be reproduced, stored in a retrieval system or transmitted, in any form or by any means, without the prior permission of the GPIAG Committee.

This journal is sent to members of the GPIAG, UK primary care faculties and NHS postgraduate centres. It is available for subscription from the publishers Strategic Medical Publishing Ltd.

For further information about the General Practice Airways Group, write to: GPIAG

Secretariat, The Medical Marketing Interface Bath Brewery, Toll Bridge Road, Bath BA1 7DE. 